\title{
Sharing the critically ill patient's information with the family: Reflections and lessons learned
}

\author{
Mokgadi C. Matlakala * \\ Department of Health Studies, University of South Africa, Pretoria, South Africa
}

Received: April 17, 2015

Accepted: June 17, 2015

Online Published: July 31, 2015

DOI: $10.5430 /$ jnep.v5n10p115

URL: http://dx.doi.org/10.5430/jnep.v5n10p115

\begin{abstract}
Objective: This article highlights the lessons learned from sharing the critically ill patient's health information with the family. The objective of the study was to explore the reflections of intensive care unit (ICU) nurses with regards to their encounters with sharing the critically ill patient's information with the family.

Methods: Four focus group interviews were conducted with purposively selected ICU nurses; and data were analysed using qualitative interpretive analysis.

Results: The findings indicated policy on dispensing patient information and enforcing patients' rights as the topics from the reflections; from which lessons were learned during sharing patient information with the families.

Conclusions: The ICU nurses learned the importance of sharing information with the families, despite the challenges inherent to maintaining confidentiality.
\end{abstract}

Key Words: Patient information, Critically ill patient, Intensive care unit nurse, Reflections, Lessons learned

\section{INTRODUCTION}

When a critically ill patient is admitted in the intensive care unit (ICU), doctors, nurses and other multidisciplinary healthcare professionals make continuous communication and share information about the condition of the patient, the prognosis and how to care for the patient throughout. Information can further be shared with different bodies such as the family, friends, the legal systems, the media and the community. The multidisciplinary healthcare professionals, including the nurses responsible for patient care should share information reliably and effectively. ${ }^{[1]}$ Often, the critically ill patients cannot speak for themselves; thus family members become the spokesperson in such instances. ${ }^{[2]}$

The nurses as the key professionals who care for critically ill patients admitted in ICU are most of the time in contact with the family members of the critically ill patients under their care. The family members are often reliant on the ICU nurses for information regarding the condition and prognosis of the patients, in the absence of the doctor. Information sharing often impact on the privacy and confidentiality of the patient's health matters.

Nurses have a moral duty to maintain the confidentiality of patient health information. ${ }^{[3]}$ Confidentiality means that personal information about a patient learnt either inside or outside of the practice situation must be kept confidential unless the patient gives consent, there is a legal justification for disclosure or where a real risk of serious harm, injury or damage exists.

\footnotetext{
*Correspondence: Mokgadi C. Matlakala; Email: matlamc@unisa.ac.za; Address: Department of Health Studies, University of South Africa, Pretoria, South Africa.
} 
Enforcing the obligation to respect rights is enshrined in the Patients' Rights Charter which indicates that everyone has amongst others the right to participation in decision making, on matters affecting own health and confidentiality and privacy of information concerning their health. ${ }^{[4]}$ Information concerning one's health, including information concerning treatment may only be disclosed with informed consent, except when required in terms of any law or any order of court. $^{[5]}$

The observation and reality is that some of the patients admitted in the ICU are not able to make independent decisions, thus the need for the family to be involved in patient health matters. The family involvement in ICU is important because the patients in ICU are critically ill and sometimes unconscious or sedated. Owing to this, the traditional nurse patient relationship is then replaced by nurse family member patient relationship. ${ }^{[6]}$ Therefore the family may need to have full disclosure of the patient's information, if they have to make medical decisions on behalf of the patients.

The general hospital policies on maintaining patient confidentiality contains declaration of confidentiality regarding patient information which indicates that all information pertaining to the patient and patient matters will be kept private and confidential. The problem is that whilst there are policies on sharing patient information in the ICUs, there is no guideline on the amount of information the family should receive from the nurses regarding the patient. Each nurse shares information as he or she deems necessary at the time.

The concerns and dissatisfaction about poor communication with providers from patients facing a life-threatening illness and their families have been documented in literature. ${ }^{[2]}$ Furthermore, anecdotal information is known about the views of ICU nurses with regards to sharing the critically ill patients' information with the families. Each new encounter of the ICU nurse with the family brings with it new experiences regarding sharing patient information. The argument in this article is that there is a need to promote an understanding of and appreciation for the complexity of sharing the critically ill patient's private information with the family. The objective of this study was to describe the reflections of ICU nurses from sharing patient information with the family. The significance of the article promises to illustrate the lessons learned from sharing patients' confidential information with the families.

\section{MeTHODS}

A qualitative verbal narrative research, following interpretivism was conducted. ${ }^{[7]}$ The researcher asked the ICU nurses to describe and reflect on their encounters of shar- ing information with their critically ill patients' families. Qualitative interpretivism was found to be relevant because the researcher sought to understand the meanings of the encounters as reflected from sharing patient information with the family. The epistemological assumption was that the participants co-create understandings of patient information and therefore can reflect on lessons learned from sharing patient information. The settings were ICUs of 3 private hospitals and 1 public hospital in Gauteng province, South Africa. The ICUS were selected on the functional capacity. The average bed capacity was 12 beds, with $100 \%$ bed occupancy rate. This meant that there were always patients in the units, and therefore the likelihood of nurses meeting with the patients families.

\subsection{Data collection}

Four semi structured focus group interviews were conducted with purposively selected ICU nurses. ${ }^{\left[{ }^{8-10]}\right.}$ The interviews took place in the rest rooms of the different ICUs where the participants worked and were audio recorded with the permission of participants. ${ }^{[10]}$ The groups comprised 4-5 ICU bedside nurses. The groups were asked to reflect on their experience of sharing patient information with the critically ill patient's family under their care at any point during their shift. All the participants had had an opportunity to address their patients' families and provided information about the patient. The interview discussion was focused more about reflection on sharing patient information, which would suggest the lessons learned in this regard. ${ }^{[8]}$ The participants were recruited on the day of data collection, based on their availability to participate in the focus group discussions, which lasted about 35 minutes.

Permission to collect data was obtained from the individual hospital authorities; and ethical clearance was obtained from the Higher Degrees Committee of the Department of Health Studies, University of South Africa. Verbal consent was obtained from the participants following a thorough explanation of the purpose of the study. ${ }^{[7]}$ Participation in the study was voluntary and the participants were informed of their right to withdraw from the study with no penalty. The participants had the same status as they were all bedside nurses and had had an opportunity to share patient information with the family at any stage of their caring for a critically ill patient9.

\subsection{Data analysis}

Audio recorded interviews were transcribed verbatim, read and coded to search for common elements from the reflections on sharing patient information. ${ }^{[7,11]}$ Through this interpretive process, the researcher set out to find out the ways through which the participants make sense of sharing patient 
information; in order to discover the lessons learned from the viewpoints held by the participants. On the spot member checking was done to ascertain agreement by the participants that their reflections have been adequately captured and that the conclusions reached in the interpretations were credible. The research design and its implementation were adequately explained. The researcher attempted to establish truth value and trust in relation to the findings of this study by using literature to control the findings. ${ }^{[12]}$

\section{RESULTS}

The results focus on the reflections and lessons learned. Two themes that emerged from the reflections on sharing patient information with the family were policy on dispensing patient information and enforcing patients' rights.

\subsection{Policy on dispensing patient information}

The participants' reflections indicated that there were policies on dispensing information to the family and visitors. In some ICUs for this study, the families were provided with information leaflets that explained the steps to follow when seeking patient information. The participants indicated that the need for patient information by the family, sometimes depend on the condition of the patient, such as when the patient is unconscious, intubated or sedated, where the family would ask for the patient information from the ICU nurses, rather than the patient self. The protocols available for dispensing of information were especially about those patients who could not give consent or talk for themselves. However, the doctors are not always in the unit, and it is difficult to measure the amount of information that should be given to the family. The participants are of a view that sometimes the families get too much information that overwhelms them; and they tend to concentrate on the information rather than spend time supporting the patient.

Nurses determine what they are willing or not willing to discuss with patients and families. ${ }^{[13]}$ The interaction between the nurses, family and the patient is based on the response as each situation is unique and need to be evaluated and managed individually. ${ }^{[14]}$ Again, it was difficult to decide with which of the patient's family and relatives' information should be shared about the patients' conditions and progress because of the diversity of individual backgrounds. Disclosure would depend on the patient's position in the family. ${ }^{[15]}$ It was also mentioned that the advantages and disadvantages of disclosure should be discussed with the patient, as disclosing information may jeopardize his/her relationship with the family. The safety of the patient should be considered before disclosure. ${ }^{[3]}$ This means that the ICU nurses should ask the patient what information should be shared, with which family members as long as it is in the patient's best interest. When confidential information is shared it should be relevant, necessary and appropriate. ${ }^{[16]}$

\subsection{Enforcing patients' rights}

The participants indicated that full disclosure of the critically ill patient's information to the family was the doctor or nurse's responsibility. The policy state that information could only be given to the closest family members such as spouse, parents or children, that is, especially about the critically ill patients who were ventilated. However, the reflection was that some visitors or relatives would always bypass the system by falsely identifying themselves as the patients' closest family members in order to receive information about the patient. Families are usually supportive advocates and concerned surrogate decision makers for patients, ${ }^{[17]}$ and are waiting for honest information. It follows that the ICU nursing staff are trying very hard to ensure confidentiality. However, because the ethical discussions are culture bound and family structures are complex; this brings about a problem of whom to share patient information with. Family wants to be informed and to participate to medical decisions. ${ }^{[18]}$ Nurses' advocacy role also brings about moral distress from ethical duty of maintaining privacy and confidentiality of patient information. Moral distress occurs when nurses are prevented from translating moral choices into moral action; such as when the ICU nurse knows the right thing to do, but is constrained by the policy on sharing patient information. ${ }^{[16]}$ Nurses often felt limited or constrained in their ability to communicate with patients and families especially around topics of code status. ${ }^{[13]}$

\subsection{Lessons learned}

The following were the lessons learned from the reflections by the participants during the focus group discussions:

Family is always important and therefore lack of communication may occur during the periods when patients are unconscious or unable to talk due to endotracheal intubation. This was reflected as the time when it becomes important for the family to have adequate information about the patient in order to take over the nurse patient relationship. Informational support on the progress and prognosis of the patient is important for the family. The participants learned that the policy on dispensing patient information should indicate clearly that the family should identify a spokesperson who will then be informed and be able to share patient information with the broader family. The participants also learned that whilst patients may be treated the same with regards to maintaining confidentiality, each family background is very different when it comes to sharing information. 
Quality of information is better than quantity of information: the participants learned that the amount of information to be shared with the family depends on the views of the individual nurses regarding what is important to tell the family at a given time; and also depends on the condition and circumstances around the patient. This brings about differences with regards to what is important, necessary and relevant to share.

\section{Discussion}

This article presented the reflections of the ICU nurses and the lessons learned from sharing information with the families and maintaining confidential information. The ICU nurses indicated the importance of sharing information with the families, despite the challenges inherent to maintaining confidentiality. Although ICU nurses spend a majority of their time communicating with patients' families, the reflections from this study demonstrated that nurses may feel constrained in their ability to share information with patients' families. On the other hand, the family may experience difficulty in understanding the information delivered by the ICU nurses. ${ }^{[19]}$ However, the family should not be excluded during care of the patient. ${ }^{[20]}$

The lessons learned are congruent with literature that healthcare practitioners seem to be aware of their duty to keep patient information but practical application poses a number of challenges. ${ }^{[3]}$ There are moral issues that affect the nurses in their practice, with reference to sharing information. However, quality of communication and information sharing between ICU nurse and the family could play an important role on the recovery of patient. Rightness or wrongness with regards to whom to share patient information with, underlie professional decision making and the beneficent of patient care, which is related to ethical duties of confidentiality, communication and the centrality of meeting patients' needs.
Nurses in ICU differ in how to respond to this ethical duty when it comes to maintaining confidentiality of information. The implication of the findings from this study is that there should be continuous robust conversations regarding patient information sharing in the ICUs in order to strengthen the policies on maintaining confidentiality and also to ensure that patients' families are not left out. Ethical and moral issues should be identified and continuously debated with the families in this regards.

\section{Conclusion}

It was important for ICU nurses to reflect on the lessons learned with regard to sharing patient information with families. The significance of the lessons learned from the reflections could be used to improve information sharing and facilitate maintaining confidentiality of patient information. Further research is recommended on the lessons learned from the nurses working in the general units, in order to ensure consistency of information that will guide the revision of policies related to patient information with the family. The sample size was very small and therefore the findings and conclusions may not be applicable to other situations and populations.

\section{ACKNOWLEDGEMENTS}

The author was responsible for the conception, design, acquisition of data, and analysis and interpretation of data, and drafting the manuscript. I would like to thank the intensive care unit nurses who shared their reflections in this study, the University of South Africa for the MDSP grant, and the individual hospital management for allowing me to conduct the study in their ICUs.

\section{Conflicts of Interest Disclosure}

The author declares that there is no conflict of interest regarding this work.

\section{REFERENCES}

[1] Caldicott DF, Manning K. A guide to confidentiality in health and social care. Health and Social Care Information Centre. 2013.

[2] Fox MY. Improving Communication With Patients and Families in the Intensive Care Unit Palliative Care Strategies for the Intensive Care Unit Nurse Disclosures. Journal of Hospice and Palliative Nursing. 2014; 16(2): 93-98. http://dx.doi.org/10.1097/NJH. 0 000000000000026

[3] Matlakala MC, Mokoena JD. Student nurses' views regarding disclosure of patients' confidential information. S Afr Fam Pract. 2011; 53(5): 481-487. http://dx.doi.org/10.1080/20786204.2011 .10874138

[4] South African Nursing Council. Nursing Act (Act 33 of 2005). Char- ter of Nursing Practice: patients' rights, nurses' rights, legal/policy framework, ethical code of conduct and commitment by Nursing. Pretoria Government Printers. 2005.

[5] Health Professions Council of South Africa. Guidelines for good practice in the health care professions. National Patients' Rights Charter. Booklet 3. 2008.

[6] Kellener S. Providing patient centered care in an intensive care unit. Nursing Standard. 2006; 21(13): 35-40. PMid:17175782 http: //dx.doi.org/10.7748/ns2006.12.21.13.35.c6388

[7] Creswell JW. Research Design: Qualitative, Quantitative, and Mixed Methods Approaches. 4th Edition. London: Sage; 2014.

[8] Barbour RS. Making sense of focus groups. Medical Education. 2005; 39(7): 742-750. PMid:15960795 http://dx.doi.org/10.1111 


$$
\text { /j.1365-2929.2005.02200.x }
$$

[9] Barbour R. Doing Focus Groups. Thousand Oaks, CA: Sage Publications; 2007.

[10] Kitzinger J. FOCUS GROUP RESEARCH: using group dynamics to explore perceptions, experiences and understandings Holloway I. (ed.) (2005) Qualitative Research in Health Care Maidenhead: Open University Press; 2005.

[11] Krueger RA, Casey MA. Focus groups: A practical guide for applied research (4th Ed.).Thousand Oaks, CA: Sage Publications. 4th ED. 2009.

[12] Lincoln YS, Lynham SA, Guba EG. Paradigmatic controversies, contradictions, and emerging confluences revisited. In: N. K. Denzin \& Y. S. Lincoln, The SAGE handbook of qualitative research (4th ed., pp. 97-128). Thousand Oaks, CA: Sage; 2011.

[13] Slatore CG, Hansen L, Ganzini L, et al. Communication by nurses in the intensive care unit: qualitative analysis of domains of patientcentered care. Am J Crit Care. 2012; 21(6): 410-418. PMid:23117904 http://dx.doi.org/10.4037/ajcc2012124

[14] Farell ME. Visiting hours in the ICU: finding the balance among patient, visitor and staff needs. Nursing Forum. 2005; 40(1): 18-
28. PMid:15839841 http://dx.doi.org/10.1111/j.1744-6 198.2005.00001.x

[15] Farrell A. Ethical issues in research with children. Maidenhead: Open University Press; 2005.

[16] Kain VJ. Moral distress and providing care to dying babies in neonatal nursing. International Journal of Palliative Nursing. 2007; 13(5): 243-248. PMid:17577177 http://dx.doi.org/10.12968/ijpn .2007 .13 .5 .23495

[17] Rothchild E. Family dynamics in end-of-life treatment decisions. Gen Hosp Psychiatry. 1994 Jul; 16(4): 251-8. http://dx.doi .org/10 . 1016/0163-8343(94) 90004-3

[18] Jacob DA. Family members' experiences with decision making for incompetent patients in the ICU: A qualitative study. American Journal of Critical Care. 1998; 7: 30-36. PMid:9429681

[19] Azoulay E, Chaize M, Kentish-Barnes N. Involvement of ICU families in decisions: fine-tuning the partnership. Annals of Intensive Care. 2014; 4: 37. PMid:25593753 http://dx.doi.org/10.11 86/s13613-014-0037-5

[20] Robinson SM, et al. Psychological effect of witnessed resuscitation on bereaved relatives. Lancet. 1998; 352: 614-617. http: //dx.doi.org/10.1016/S0140-6736(97) 12179-1 